\title{
G.M. Turchini, W.-K. Ng and D.R. Tocher (eds): Fish oil replacement and alternative lipid sources in aquaculture feeds
}

\author{
CRC Press (Taylor \& Francis), Boca Raton, 2011, XVIII + 533 pp, \\ $£ 95 /$ US\$149.95 (Hardback), ISBN 978-1-4398-0862-7
}

\section{Malcolm Jobling}

Received: 6 August 2010/ Accepted: 6 August 2010/Published online: 19 August 2010

(C) The Author(s) 2010. This article is published with open access at Springerlink.com

Within the space of just over 500 pages, made up of 15 multi-author chapters, this book provides a comprehensive overview on the production and use of fish oils, vegetable oils, terrestrial animal fats, and several unconventional lipid sources in finfish aquaculture and the aquafeed industry. All chapters are tightly packed with factual information, and all are also extensively referenced, with quite a strong emphasis on recently published review articles, original papers, and reports. The editors express a hope that the book will serve as a reference work for nutritionists, oil chemists, seafood processors and suppliers, policy makers and personnel involved with agriculture, fisheries, aquaculture, and the aquafeed and edible-oil industries; practitioners in most of these areas will find something of value in the book, but some will almost certainly have much of the information already to hand in the form of published reviews and via access to websites. As such, the main value of the book may not be in the new information it contains (which is rather limited), but in the fact that it draws together so much relevant information within a single volume.

The book is made up of three interconnected parts, comprising three, seven, and five chapters, respectively. The first chapter provides readers with a global overview on the production and use of oil sources in aquaculture and the aquafeed industry, including a retrospective covering the development of the culture of intensively farmed species, and the concomitant increase in the need for feed ingredients. Chapter two is a primer in lipid and fatty acid biochemistry, and chapter three gives an overview of current oil usage by the aquaculture industry and a brief discussion relating to some thorny issues and controversies surrounding the use of various oil sources. Following this opening gambit, there are seven chapters that look at specific oil sources in detail; production and supply, chemical characteristics and advantages and disadvantages as aquafeed ingredients. The final five chapters of the book consider the effects of various oil sources, their fatty acids and other components, on the growth, metabolism, health and welfare, and post-harvest qualities and attributes of farmed fish. The overall structure of the book has been well thought out, and the chapters follow in a logical sequence, making it relatively easy for the reader to find a clear path to follow.

M. Jobling ( $₫)$

University of Troms $\emptyset, 9037$ Troms $\emptyset$, Norway

e-mail: malcolm.jobling@uit.no 
One possible downside with the book is that cultured finfish, and in particular salmonids, tend to dominate the coverage, and somewhat overshadow other animal groups, such as crustaceans. In addition, a number of overviews of lipid nutrition and oil use in aquaculture have been published relatively recently; several of these have been written by contributors to this book. This means that most of the information presented in the book is already widely available in a form that will be accessible to most fish nutritionists and aquaculture researchers.

Turning to questions relating to technical presentation; the organization of many of the figures is poor, and the reproduction is frequently very poor, and some of the tables can be criticized as having a rather haphazard and cumbersome presentation. There are a few printing errors, such as the use of phosphorous when phosphorus is correct (a mistake that appears more than once), and there are some cases of inconsistent presentation of units. One or two errors in syntax, and in the presentation of equations and formulae, were also noted along with a few instances of incongruous phraseology, some mistakes in citation and also occasional lack of concordance between text citations and reference lists. In addition, there are a number of incorrect spellings of the formal names of fish species, fish species' names are not used consistently across chapters and there also seem to be one or two cases of mistaken identity.

Some information is presented several times even though there is a reasonable degree of cross-referencing between chapters. The amount of repetition is something that could be a source of minor irritation if several chapters are read at a single sitting, but the repetition may go unnoticed if chapters are read in isolation, or if the book is used primarily as a quick source of reference; being dipped into to find a specific piece of information or for confirmation of a particular fact.

Considering the book as a whole, the positives outweigh the negatives by a reasonable margin, and it can be concluded that Fish Oil Replacement and Alternative Lipid Sources in Aquaculture Feeds is a most useful compilation that goes a good way down the path of fulfilling its intended purpose. The book presents key, up-to-date information about the importance of lipid nutrition in finfish aquaculture, and about the availability and use of oil sources in the production of aquafeeds. Its main advantage is that the information is collected in a single volume, so the book is likely to become a standard source of reference for fish nutritionists and other aquaculture professionals.

Open Access This article is distributed under the terms of the Creative Commons Attribution Noncommercial License which permits any noncommercial use, distribution, and reproduction in any medium, provided the original author(s) and source are credited. 